\title{
The Effects of Sodium Hydroxide (NaOH) Surface Treatment on Dried Banana Leaves Fibre (DBLF) to Prepare and Characterize Degradable Plastic Materials with waste Polypropylene
}

\author{
Thinakaran Narayanan ${ }^{1,2 *}$, Jeefferie Abd Razak ${ }^{1}$, Intan Sharhida Othman ${ }^{1}$ \\ ${ }^{1}$ Fakulti Kejuruteraan Pembuatan, Universiti Teknikal Malaysia, Melaka, Hang Tuah Jaya, Malaysia \\ ${ }^{2}$ Department of Mechanical Polymer, National Youth and High Skill Institute (IKTBN) Sepang, Bandar Baru Salak Tinggi, Malaysia \\ *Corresponding Author: Thinakaran Narayanan, Department of Mechanical Polymer, National Youth and High Skill Institute (IKTBN) \\ Sepang, Bandar Baru Salak Tinggi, Malaysia.
}

Received: August 08, 2019; Published: August 22, 2019

DOI: 10.31080/ASAG.2019.03.0628

\begin{abstract}
Disposal of the after-used plastic-based product has created worldwide problems on environmental pollution. This scenario has initiated the inventiveness to develop eco-friendly biocomposites products. In this research, recycled waste polypropylene (rPP) was loaded with dried banana leaves fibre (DBLF), for rPP/DBLF composites fabrication. The effects of sodium hydroxide (NaOH) treatment on DBLF has studied based on the resulted mechanical and fracture morphological properties of produced rPP/DBLF composites. Dried banana leaves have been ground into $30 \mu \mathrm{m}$ of fibre length, and rPP was taken from injection moulding scrap and crushed into finer rPP particles. The rPP/DBLF composites are prepared through double steps compounding method by using a melting device $\left(230^{\circ} \mathrm{C}, 95 \mathrm{rpm}, 60 \mathrm{mins}\right)$ followed by an injection moulding process $\left(210^{\circ} \mathrm{C}, 30\right.$ seconds of residence time) for various amount of treated and untreated DBLF fibre loading at 0, 10, 20, 30 and $40 \mathrm{wt}$. \%. It was found that the tensile strength (TS) of treated NaOHrPP/DBLF composite has significantly increased into about $+45.20 \%$ with $30 \mathrm{wt}$. $\%$ of DBLF-NaOH loadings, in comparison to the unfilled rPP sample. Loading of NaOH treated DBLF into $\mathrm{rPP}$ was enhanced the strength result which indicates successful reinforcement effects introduced by DBLF-NaOH filler. This could be explained by finer DBLF particle morphology as observed by SEM and presence of $\mathrm{OH}$ group from the successful $\mathrm{NaOH}$ treatment, which responsibly encouraged the mechanical interlocking and chemical bridging with rPP, for improved matrix-filler interaction, that significantly increased the TS. In overall, this study has successfully highlighted the potential of DBLF filler to enhance the properties of rPP, as an additional choice of degradable plastic-based composite for various promising applications.
\end{abstract}

Keywords: rPP; DBLF; Degradable Plastics; Tensile; Fracture Surfaces; NaOH Surface Treatment

\section{Introduction}

A wide-ranging application of thermoplastic materials has stricken most current industries, such as manufacturing industry, transportation industry, medical industry and many more other industries [1]. Due to plastic flexibility characteristic, the utilization of petroleum-based non-biodegradable plastic is turn out to be endless. This scenario has cultivated the important of postproduction on waste plastic, combined with natural fibres, which are currently available and feasibly being consumed as a secondary phase of the polymer matrix composites (PMC). The resulting composite also known as green composites. The bio composition between waste plastic and natural fibres have superior and outstanding mechanical properties as well as physical properties [2]. Thermoplastic materials have been increasingly used for various applications [1]. In this research, the waste from injection moulding scrapped was consumed as a matrix and the plant-based natural fibres have been utilized to reinforce the matrix phase.
Natural fibres which were extracted from plant-based are very attainable and abundant resources to substitute for high cost and non-renewable synthetic fibres [1]. Natural fibres acquired low cost, low density, non-toxicity, possessed comparable strength and almost no waste disposal issues [2]. As we know, among the Southeast Asia nations, Malaysia having varieties of plant-based fibres including coconut coir fibres, kenaf fibres, palm oil empty fruit bunch, banana fibres, pineapple fibres, etc. At this time, the consumption of plant-based natural fibre is very popular and common in numerous engineering applications, such as in telecommunication, electrical and electronic industry [3]. The incorporation of natural fibres and waste recycled polypropylene (rPP) have extremely improved the mechanical strength of produced composites [4]. In this study, dried banana leaves fibre (DBLF) has been utilized as a secondary phase for rPP matrix which was produced from an injection moulding process. So such a reason, the waste polypropylene was taken from an injection moulding operation and was 
ground into fine particles by using an industrial crusher. Then, several compounding step and hot compression technique were applied for rPP/DBLF composites production.

The cultivation of banana crops such as leaves, trunks, peels, etc. was becoming a primary factor causing more residue generated from an agricultural industry and these causes harmful threat to the environment [7]. Banana leaves rich in starch and contents cellulosic fibres and lignin [5]. Cellulosic based fillers have been of superior interest that will offer a great improvement to biocomposites mechanical properties, as compared than those composites containing non-fibrous fillers [6]. The matured banana leaves contain dry matter protein, lignocellulose fibres, starch as well as moisture [7]. The banana tree yields a big quantity of cellulosic residue which disposed into a landfill [7]. During this degradation process, dried banana leaves emitted about $20 \%$ of methane gaseous which is 84 times more harmful than carbon monoxide, which is one of the main reason for global warming [8]. Besides, DBL can be used for industrial purpose without any extra cost [4]. In this study, DBL was derived from post-harvest of the banana tree. Dried DBL was ground by using a laboratory blender for converting it into DBLF powder. For this reason, to understand the role of DBLF as latest green functional filler for polymer matrix composites, their chemical treatment effects to the resulted mechanical and fracture morphological of rPP/DBLF composites were studied in this preliminary research.

\section{Materials and Methods \\ Raw materials}

The materials used in this experiment for packaging application are recycled polypropylene (rPP) and dried banana leaves (DBL). rPP are collected from the waste generated by an injection moulding process in IKTBN Sepang. The purging of waste has been generated from teaching and learning activities held in the polymer processing laboratory at IKTBN Sepang. The rPP was originally virgin homopolymer polypropylene delivered by Titan PP Polymers (M) Sdn. Bhd. The collected rPP scrapped was first cleansed and isolated for any contamination or impurities elimination. Next, the rPP was filled into an industrial crusher machine for grinding into fine particles. The process was repeated about two times to ensure rPP sizes homogeneity.

The dried banana leaves fibre were derived from dry banana petiole (one of the parts from banana leaves) of Musa acuminate sp. species. The petiole was separated from dried banana leaves then treated with sodium hydroxide $(\mathrm{NaOH})$, that was heated at $80^{\circ} \mathrm{C}$ for 30 minutes. The DBLF was further dried in a drying oven for 24 hours at $80^{\circ} \mathrm{C}$ for conditioning purpose. Next, the DBLF was ground by using an industrial blender and filtered into $30 \mu \mathrm{m}$ of length size with Analysette 3 vibratory sieve shaker. Lastly, the merging process of rPP/DBLF composites was performed via double steps of the melt-blending process.
rPP/DBLF composites preparation via double steps meltblending procedure

The rPP/DBLF composites with treated and untreated DBLF with numerous different loadings $(0,10,20,30$ and $40 \mathrm{wt} . \%)$ were formulated to evaluate the effects of sodium hydroxide $(\mathrm{NaOH})$ surface treatment to the rPP filler for composites application. The double-steps melt-blending method was applied to combine the $\mathrm{rPP} / \mathrm{DBLF}$ composites. In the beginning, the tuned melting device was set into $230^{\circ} \mathrm{C}$ and mixing was performed within the period of 60 mins at $95 \mathrm{rpm}$. Later on, the second melt-blending phase was followed by injection moulding and the samples were injected into a specific dimension and shape of samples for tensile test. The moulding process was performed at $210^{\circ} \mathrm{C}$ within $30 \mathrm{sec}$ of residence period, using DKM-188 Dakumar type injection moulding machine. Produced samples were conditioned at $80^{\circ} \mathrm{C}$ for $24 \mathrm{hrs}$ in a drying oven, before carrying out the subsequent mechanical testing.

\section{Fourier transform infrared spectroscopy}

The Fourier transform infrared (FTIR) spectroscopy technique was used to characterize the chemical structure for treated DBLF fibre with $\mathrm{NaOH}$ and untreated DBLF fibre. This analysis will determine the variations in the measurement of fibre composition before and after the $\mathrm{NaOH}$ chemical treatment. Each spectrum was recorded in the range of $3600-400 \mathrm{~cm}^{-1}$ at a resolution of $4 \mathrm{~cm}^{-1}$ with 32 scans using an FTIR machine model JASCO FT/IR-6100 type A.

\section{Tensile Testing of rPP/DBLF composites}

The tensile test for rPP/DBLF composites was performed following ASTM D638 - Type 1. The dimension of the tensile test sample was monitored within $\pm 1.00 \mathrm{~mm}$ of thickness, an overall width of $19.00 \mathrm{~mm}$ and gauge length at $50.00 \mathrm{~mm}$. The test was carried out at a controlled atmosphere of $22 \pm 1^{\circ} \mathrm{C}$, at a relative humidity of $60 \%$. Testing was performed at $10 \mathrm{~mm} / \mathrm{mins}$ of cross-head speed by using a Universal Testing Machine (GoTech). For each loading, about five samples were tested for data averaging purpose. For the case of this study, only tensile strength (TS) response was analysed and presented, to represent the reinforcement effects and properties improvement due to $\mathrm{NaOH}$ surface treatment performed towards DBLF green filler.

Fracture surface morphological observation of rPP/DBLF composites

The fracture surfaces of the selected samples of rPP/DBLF composite was observed under the Scanning Electron Microscope (SEM) observation. At first, the fractured surface was mounted onto the stub with carbon tape before being coated with goldpalladium (Au-Pd) thin conductive coating, using a sputter coater model Polaron E-1500, to eliminate the charging effects during observation. The fracture surface images were captured by using 
Zeiss Evo VPSEM at 7.00kV accelerating voltage for 100x of magnification power at secondary electron detection.

\section{Results and Discussion}

The FTIR spectra of untreated and $\mathrm{NaOH}$ treated DBL fibre are as depicted in Figure 1. NaOH treated DBLF fibre is referred to as the red plots while the black plots belong to the untreated DBLF fibre. The spectrum of DBL fibre is subject where the dominant peak at $2987 \mathrm{~cm}^{-1}$. The peak at about $2900 \mathrm{~cm}^{-1}$ is referring to the $\mathrm{C}-\mathrm{H}$ asymmetric and symmetric stretching from aliphatic saturated compounds which is parallel to the aliphatic moieties in cellulose and hemicellulose. Instead, the peaks in the region $1455 \mathrm{~cm}^{-1}$ are due to $\mathrm{C}-\mathrm{H}$ groups from various lignin. The intensity of the peak at $1366 \mathrm{~cm}-1$ is sharply reduced after the presence of $\mathrm{NaOH}$ which is indicating $\mathrm{C}-\mathrm{H}$ groups in methyl and phenolic alcohol and results from bending vibration in the molecule. Apart from that, the peaks found at $1145 \mathrm{~cm}^{-1}$ and $893 \mathrm{~cm}^{-1}$ for untreated DBL fibre looks disappear at peak for $\mathrm{NaOH}$ treated. Different IR peaks at between untreated and treated DBLF has explained evidence of the success in performed alkaline treatment done into DBLF fibre.

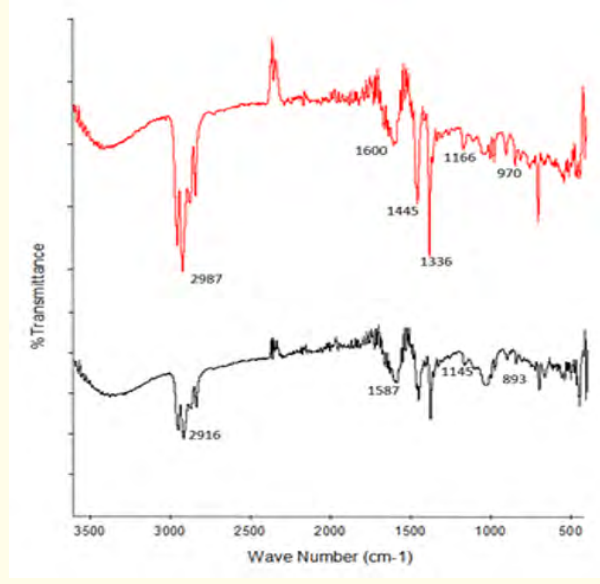

Figure 1: FTIR spectrum for $\mathrm{NaOH}$ treated DBLF (red line) and untreated DBLF (black line).

The main aim of this investigation is to indicate the effectiveness of $\mathrm{NaOH}$ treatment towards the mechanical strength of produced rPP/DBLF composites (Figure 2). Apart from mechanical properties, the effect of $\mathrm{NaOH}$ on the fractured chemical structure of rPP/ DBLF composite has been observing via scanning electron microscopy (SEM). The following Figure 2 has presented the resulted tensile strength (TS) for rPP based composites filled with $\mathrm{NaOH}$ treated DBLF and untreated DBLF at various loadings (wt.\%). It was found that, by treating DBLF with $\mathrm{NaOH}$ into rPP matrix, the TS was significantly increased up to $+45.20 \%$ of improvement (refer to the green plot), in comparison to the untreated DBLF sample. This absolute improvement was due to the special ability of treated DBLF with $\mathrm{NaOH}$ that has improved the mechanical strength of produced rPP/DBLF composites. The alkaline treatment introduced to DBLF filler able to enhance the compatibility of DBLF which later provide the reinforcement effect into rPP matrix. However, this improvement is only applied up to $30 \mathrm{wt} . \%$ of DBLF addition, for both treated and untreated rPP/DBLF composites systems. Addition of DBLF filler more than this amount has reduced the performance of the composites, which responsible for lowering the TS values. This properties reduction is due to agglomeration of DBLF where the dispersion of filler was not effectively taken place at maximum loading. Agglomeration of DBLF filler has responsible in avoiding the homogeneous load transfer during the tensile loading and prone to crack zone at the agglomeration site has caused the early premature failure of produced rPP/DBLF composites.

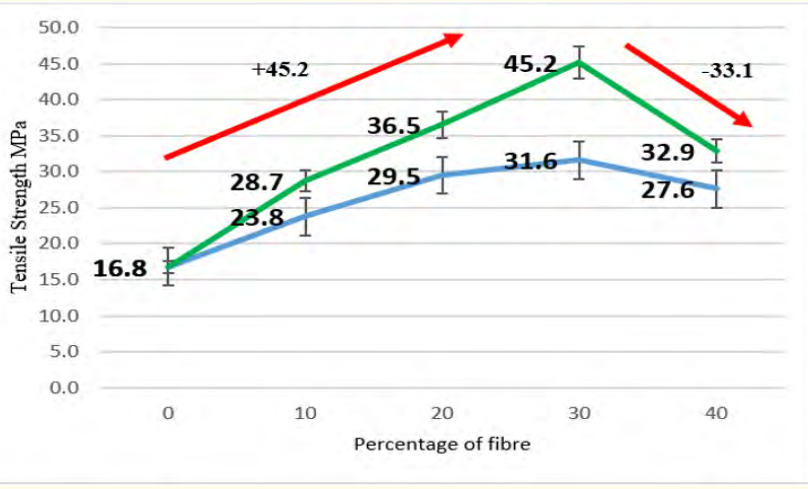

Figure 2: TS plots for $\mathrm{NaOH}$ treated (green line) and untreated (blue line) DBLF at different wt \% of loadings in rPP based composites.

The fracture morphology of rPP/DBL composites was analysed to evaluate the effects of $\mathrm{NaOH}$ treatment into DBL fibre reinforced rPP at different loadings. This probe was investigated by referring based on the fracture surface of the tensile specimens. For untreated composition, it indicates very ineffective fibre matrix binding which is supported by the presence of cavities between fibre and the matrix and fibre pull-outs due to weak compatibility as displayed in Figure 3(b). Meanwhile, the comportment of the $\mathrm{NaOH}$ compatibilizer provides enhanced progress of the wettability of both fibre surface by the rPP matrix. The gaps between both composites were very less which is indicating superior adhesion and excellent wettability between the fibre and matrix as proven in Figure 3(a). The effective diffusion for the period of blending avoids the unused area, thus it was indicated by providing the superior mechanical properties compared to composites without the presence of treated DBLF- $\mathrm{NaOH}$ as filler inclusions. 

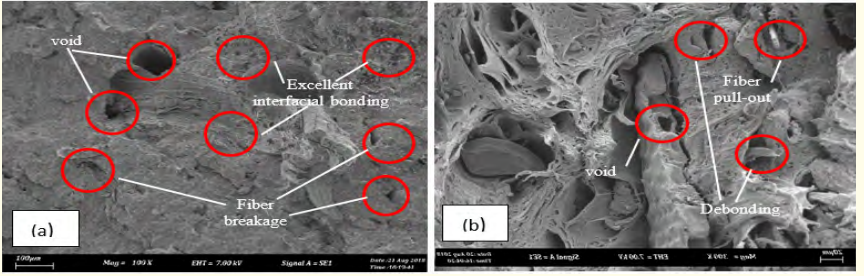

Figure 3: Rough and coarse texture morphology of DBLF (100x mag).

\section{Conclusion}

In conclusion, from this study, the effects of DBLE fibre loadings, as well as the effect of $\mathrm{NaOH}$ alkaline treatment towards the investigated tensile and fracture morphological properties of rPP/ DBLF composites, were fully explored and understood. Based on the experimental results, it was found that about $30 \mathrm{wt} \%$ of treated DBLF addition has enough to enhance the TS for positive improvements compared to untreated DBLF. This study has successfully revealed that the improved interfacial adhesion and matrix-filler interaction, introduced by $\mathrm{NaOH}$ treated DBLF filler, are successfully enhanced the properties of rPP based composites. These positive findings provide another alternative of the degradable plasticbased composite to be selected and utilized for various promising applications.

\section{Acknowledgments}

Authors would like to extend their sincere appreciation to Ministry of Education, Malaysia (MOE) and Universiti Teknikal Malaysia Melaka (UTeM) for funding and supporting this research work under the FRGS research grant - FRGS/1/2018/TK05/ UTEM/02/4. Sincere thanks to Faculty of Manufacturing (FKP), UTeM and Mechanical Polymer Department, IKTBN Sepang, for extensive support on laboratory and facilities until the completion of this research works.

\section{Bibliography}

1. Ramesh M., et al. "Processing and Mechanical property evaluation of banana fibre reinforced polymer composites". Procedia Engineering 97 (2014): 563-572.

2. Yion S., et al. "Mechanical properties of recycled plastic fibres for reinforcing concrete". Fibre Concrete (2013): 1-10.

3. Bolka S., et al. "Thermal and mechanical properties of biocomposites based on green PE-HD and hemp fibers". Contemporary Materials VIII-1 (2017): 80-90.

4. Batori M., et al. "Production of pectin-cellulose biofilms: A new approach for citrus waste recycling". International Journal of Polymer Science (2017): 1-7.
5. Mohapatra D., et al. "Banana and its by-product utilisation: An Overview". Journal of scientific and industrial research 69.5 (2010): 323-329.

6. Marikkar JMN., et al. "Evaluation of banana (Musa sp.) flowers of selected varieties for their antioxidative and anti-hyperglycemic potentials". International Food Research Journal 23 (2016): 1988-1995.

7. Mukhopadhyay S., et al. "Banana fibres - variability and fracture behavior". Journal of Engineered Fibers and Fabrics 3 (2008): 39-45.

8. Abd Razak J., et al. "Effects of poly(ethyleneimine) adsorption on graphene nanoplatelets to the properties of NR/EPDM rubber blend nanocomposites". Journal of Materials Science 50.19 (2015): 6365-6381.

\section{Volume 3 Issue 9 September 2019} (c) All rights are reserved by Thinakaran Narayanan., et al. 